\title{
Understanding the constraints, needs and aspirations of Samburu pastoralists in a decentralized animal health project in Kenya
}

\author{
K. Ilest
}

Intermediate Technology Development Group, PO Box 1931, Meru, Kenya

\section{Introduction}

Kenya is situated on the equator of eastern Africa. Seventy per cent of the country is arid rangeland where the majority of people derive their livelihood from pastoralism. The Intermediate Technology Development Group (ITDG) began work in this region in Baragoi division of Samburu district in mid 1989 as part of a larger OXFAM project.

Baragoi division is $5500 \mathrm{~km}^{2}$ in size and has a population of 30500 . The area is characterized by scrubland, dwarf bushes and acacia trees. The average annual rainfall of $700 \mathrm{~mm}$ is unreliable and highly localized. Most people are Samburu and depend on livestock for food, cash for the purchase of food and other commodities, clothing, household goods and social functions. They keep cattle, goats, sheep, donkeys, and more recently camels which are used for milk and meat.

OXFAM started working in the area in 1985 by restocking families left without animals after the drought of 1984. Subsequently many of these animals died, and the restocked families asked for help. It was to help with this problem that OXFAM asked for ITDG's assistance.

To do this it was necessary to gain an understanding of the socio-economic, political and technical factors affecting livestock production in general and animal health in particular. Baseline data was also needed for monitoring and evaluation purposes as well as to disseminate information about innovations.

\section{Material and methods \\ Collecting the information}

Pastoralists have an intimate knowledge of their environment, a deep understanding of the factors limiting livestock production (and therefore affecting their livelihood) and strong opinions on how to deal with them. For this study a number of participative

+ Present address: ITDG, Myson House, Railway Terrace, Rugby. data collection methods were employed including informal discussions and observation, wealth ranking, household questionnaires, and ethnoveterinary and progeny history question lists.

First discussions were held with individuals and groups of pastoralists, OXFAM staff, government staff, and other non-governmental organizations working in the area. These discussions, a literature review and observation of husbandry practices at settlements provided enough information to identify specific areas for more detailed investigation or quantification. These included the use of veterinary medicines, the incidence of specific diseases, and the action taken when an animal falls sick.

A wealth ranking technique was used to select rich, average and poor households to be interviewed using the household questionnaire, ethno-veterinary and progeny history question lists. Wealth ranking also provided an informal opportunity to explore factors affected by wealth such as management practices, access to grazing, labour and veterinary services and the transfer of knowledge and skills between richer and poorer households. Wealth ranking acts as a card-sorting technique in which the name of each household head is written on a card and several informants are asked to place cards in piles according to their perception of that household's wealth. People enjoy doing this and once the cards are organized into piles are usually happy to discuss the characteristics of households in each pile, including how many animals they have and relationships between houscholds in different piles.

A short household questionnaire was used to collect additional information on livestock management, major problems with livestock keeping, the action taken when an animal falls sick, and the use of traditional and modern medicines.

Progeny histories were used to collect information on offtake and mortality of adult females in the herd, focusing specifically on the origin of animals, 
number of births and the fate of offspring. They provided quantitative information from a large number of animals on the voluntary offtake (sales, exchange, gifts), losses due to diseases and other causes such as drought and theft, and indicators of fertility and herd structure. The technique is popular with livestock owners, who like talking about their animals and can provide quantitative data on a large number of animals in a short time.

Ethno-veterinary question lists were used to explore the existing level of veterinary knowledge. This is a semi-formal interview about a specific disease including questions on the symptoms, species affected, cause, traditional and modern treatments and their efficacy.

\section{Results}

The survey demonstrated that pastoralists in Samburu can recognize a wide variety of livestock diseases but are less certain of their cause. Some pastoralists are using modern veterinary medicines but are uncertain of which drug to use to treat which disease, how to give it, and the dose rate. Drug supply to the area is intermittent and unreliable and drugs are usually only available in two major towns.
The information indicated that simple diseases such as worms and ticks were a major cause of loss of production.

These findings were discussed with the communities concerned, and their comments and suggestions incorporated in the design of the project. The resultant project focuses on training in the treatment and prevention of diseases using modern veterinary medicines and on improving drug supplies in the area. The training takes place in pastoralists' own settlements, is based on practicals and discussions and concentrates on the commonest diseases. The drug supply has been improved by expanding an existing shop in Baragoi town.

In the 7 months since training began approximately 300 people have been trained to treat six common diseases. An estimated 45000 animals have been treated with drugs purchased from the shop, mostly anthelmintics to treat worms in goats and sheep. The training is popular and one of the trainees has started taking drugs purchased in the shop to sell to others in more remote parts of the area, and it is hoped that this will develop to make the drugs more widely available. 